\title{
Les Luthiers a 50 años de Blancanieves y los siete pecados capitales
}

\section{(Josefina Vargas Fonseca \\ Universidad Nacional de Córdoba, Argentina \\ josevarfon7o@gmail.com}

Fecha de recepción: 19/11/2019. Fecha de aceptación: 17/02/2020.

\begin{abstract}
Resumen
Al cumplirse cincuenta años de la representación teatral experimental Blancanieves y los siete pecados capitales (Oratorio Profano) de Les Luthiers con cantantes y actores, se pretende destacar los aciertos de la propuesta que incluía recursos tecnológicos audiovisuales fruto de las experiencias realizadas en el Instituto Di Tella puestas al servicio del teatro. Ante los avances posteriores y el vasto desarrollo de las investigaciones teatrales, esta obra muestra intentos por revitalizar un signo teatral complejo que entable una comunicación teatral renovada. Las demandas de una generación joven, afectada por profundos cambios culturales de fines de los 60, encuentran un discurso humorístico-musical en un ensamblaje de la escena con proyección de diapositivas, recursos audiovisuales, instrumentos formales e informales; en un intercambio interdisciplinario exitoso que se ha prolongado en el tiempo.
\end{abstract}

Palabras clave: Les Luthiers, cincuentenario, Blancanieves, Instituto Di Tella, innovación teatral.

\section{Les Luthiers Fifty Years after Snow White and de Seven Deadly Sins}

\begin{abstract}
Fifty years after the pemiere of Snow White and the Seven Deadly Sins (Profane Oratory), Les Luthiers' experimental theatrical performance with actors and singers, this article aims to highlight the interesting achievements of this work, which included audiovisual technological resources, putting some of the experiences of the Di Tella Institute in the service of theatre. While many advances in theatrical investigations were still waiting to happen, this work shows early attempts to revitalize a complex theatrical sign and to renew theatrical communication. Thus, the demands of a young generation, affected by profound cultural changes in the late 6os, find a the way to a humorous-musical discourse based on an assembly of the theatrical stage
\end{abstract}


with slide pictures, audiovisual resources and formal and informal instruments in a sucessful interdisciplinary exchange that has lasted over time.

Keywords: Les Luthiers, Fiftieth Anniversary, Snow White, Di Tella Institute, Theatrical Innovation.

La Biblioteca de la Universidad Di Tella guarda la documentación perteneciente a esta creación teatral; registros y testimonios que devuelven la memoria hacia una valoración en perspectiva, cuando las innovaciones y su originalidad consagraron al grupo Les Luthiers a partir de aquellas experiencias en el teatro experimental, en busca de un estilo humorístico-musical que los identifica.

Mucho se ha escrito sobre la producción artística de la década del 6o; sin embargo, muchas actividades han sido ignoradas quizás por el cierre repentino del Instituto Di Tella a comienzos de los 70 y las consecuencias de los conflictos políticos con la dispersión de los artistas y sus obras. El caso de Blancanieves y los siete pecados capitales (Oratorio Profano) de Les Luthiers, suspendida en 1970, ha dejado algunos rastros de las circunstancias que pretendemos rescatar del olvido. Los propios Luthiers la han dejado atrás por la definición de otros espectáculos que profundizan el estilo hasta la actualidad.

Siguiendo los rastros del cincuentenario, al volver el tiempo atrás, sus nombres permanecen en una placa recordatoria en la calle Florida con fecha 1967, cuando ingresaron al Instituto Di Tella a desplegar la actividad artística, como instancias previas a Blancanieves..., un proyecto compartido con músicos, cantantes y actores.

Recordando la actividad artística en 1969 , en el contexto del Di Tella, se preparaba Blancanieves y los siete pecados capitales (Oratorio Profano). Dos años antes, Gerardo Masana, Daniel Rabinovich, Jorge Marona y Marcos Mundstock, integrantes del grupo, registraban éxitos corales y algunas presentaciones bajo el nombre de I Musicisti, adaptando composiciones operísticas. Durante esa etapa se producían cambios, inclusive en el nombre del grupo con diferencias de criterio entre sus integrantes en momentos en que presentaban Les Luthiers cuentan la ópera, buscando así la consolidación actoral. Simultáneamente, habían comenzado algunas grabaciones acompañados con libros y algunas presentaciones de televisión en Canal 7 concretadas en 1968. Favorecidos por las inquietudes corales del momento pudieron desarrollar un talento propio, fruto de las prácticas diversas; destacando siempre la presencia de los instrumentos informales y el humor, que los han inmortalizado en su arte. Era favorable el clima en el Di Tella que puso al alcance de los jóvenes un espacio para generar estas nuevas puestas en escena basadas en una "intertextualidad paródica de lenguajes verbales y sonoros, el humor y los juegos de palabras" (Trastoy y Zayas de Lima, 2006: 171).

Ya desde su estreno, el 14 de agosto de 1969, el enunciado del título contenía incoherencias humorísticas vinculadas al cuento tradicional o inclusive a las imágenes de Walt Disney en que la personalidad de la protagonista se asocia a la niñez, la inocencia, por las condiciones de princesa en un universo enfrentado a la tentación de los pecados que profundizan la dicotomía de los cambios sociales emergentes en el mundo por aquellos años.

Hacia fines de la década, se venía produciendo una crisis en la Fundación Di Tella, por lo cual se decidió buscar atractivos en obras "inmediatamente populares como Anastasia querida de Nacha Guevara y Blancanieves y los siete pecados capitales de Les Luthiers, explica John King; marcando un cambio de rumbo, en algunas canciones que "ironizaban sobre el clima moral imperante", Por caso la referencia a "Cortate el pelo, muchacho"; canción interpretada por Nacha en su espectáculo (King, 2007:262 
). Con ese criterio compartían un programa teatral que aparecía en los periódicos en la sección espectáculos. Un dato importante porque en el mismo espacio se había impuesto la censura para Nacha Guevara como prohibido para menores de 13 años.

En el caso de Les Luthiers, la búsqueda de lo popular se orientaba íntimamente ligada al humor, como estrategia de cuestionamientos sobre la actualidad en confrontación con la cultura tradicional. El clima de innovación humorístico-musical era favorecido por la experimentación teatral, un rasgo fundamental en los artistas de esa época, en el al Instituto. Allí se vivía una expansión del arte que influyó en nuevos conceptos de dramaturgia. Una búsqueda de cambios que cristalizaron en los happenings, alentados por otras experiencias extranjeras, combinando diferentes sistemas expresivos como formas híbridas de teatro arte.

La incorporación de los medios masivos de comunicación, asimilados a la vida cotidiana, se transformaron en nuevos recursos buscando interactuar con un espectador participante, estimulado por las innovaciones escenográficas. Todos recursos que aplicaron en la representación.

Hacia 1969, dispuestos a concretar el proyecto para Blancanieves y los siete pecados capitales (Oratorio Profano), invitaron a participar a Carlos Nuñez Cortés y a otros cantantes y actores para lograr los perfiles actorales que demandaba la adaptación humorística-musical del cuento aludido. Pronto se encontraron interactuando con cantantes líricas y actores profesionales, tal el caso de Julio López, cuya trayectoria fue enriqueciendo la versión primera, apenas un bosquejo de ideas que finalmente se convirtió en un guión escrito.

Con diferente capacitación y estilos actorales se produjo un auténtico arte híbrido de experimentación, que enriqueció la actuación entre medios televisivos, recursos de la voz en off, instrumentos formales e informales interpretados en el marco teatral, donde a partir de un escenario despojado, no convencional, desplegaban su capacidad actoral, coral y musical, produciendo una escenografía que transformó el signo teatral al entrar en contacto con otros efectos que modificaron el rol de los actores.

El trabajo cooperativo sin texto inicial, sin director y siguiendo sus aportes sobre la actuación, produjo cierta desorientación en los primeros ensayos, hasta tomar conciencia de la necesidad de un guión más estable. Esta incertidumbre ha sido relatada por el actor Julio López en oportunidad de su incorporación:

Les Luthiers, con alguna que otro cambio, se disponía a llevar a cabo una idea sobre Blancanieves. Todo en base a acuerdos. Hay que recordar que el grupo Les Luthiers apenas se estaba consolidando en esa fecha, estaban en un proceso de asimilación, si lo miramos desde la actualidad. Me asignaron el papel del Guardabosques, con algunas sugerencias y mucha libertad para crear el personaje.

Les Luthiers venían con otras ideas sobre el espectáculo, que definitiva triunfaron (...) al principio [hubo] una gran tensión porque ellos, desde otra capacitación, confrontaban con el "libreto". Apenas comenzaron los ensayos, todos en base a opiniones. Así surgió un conflicto por las diferencias de formación y les dije que no estaba dispuesto a seguir. Estaba desorientado por mi formación actoral ajustada a un libreto pautado. En este caso, Marcos Mundstock era quien llevaba a cabo la coordinación de la obra, pero ni con su guía se podía continuar. Entonces, le dije, yo no me adapto a esto y si no se modifica el trabajo, yo no vengo más. Fue así, que se suspendió el ensayo como por diez o quince días. iiHasta que luego de ese tiempo, me llamó nuevamente Mundstock para decirme que tenía listo el 
libreto!! Yo no podía creerlo. Y más asombro me causó comprobar la excelencia de la obra que no me imaginaba que podían reconstruir de manera organizada. Con el texto reiniciamos los ensayos. (Entrevista personal a Julio López en Buenos Aires, el 22 de octubre 2010)

Resulta trascendente poder revivir los hechos desde la actualidad, dimensionar el proceso entre tantos estudios interesados en esclarecer los problemas entre la representación y el texto. El grupo prefirió presentarse al desafío de la puesta en escena a través de la experimentación como aprendizaje y búsqueda de una estética propia. En el proceso de reelaboración del guión surgieron dos copias mecanografiadas con modificaciones del comienzo, hasta la copia definitiva registrada.

Evaluando el contexto de la época, acordamos con Zayas de Lima (1995:15-17) en el auge de nuevos grupos en un movimiento teatral muy intenso de actores, directores, escenógrafos, vestuaristas, donde se mezclan técnicas de actuación en un "gusto por la libre experimentación". Concluye que "durante toda la década continuarán las polémicas entre los críticos, el público, los dramaturgos, los directores y actores entre realistas y absurdistas y los que habían elegido la experimentación abundando recíprocas críticas e invalidaciones". Este cuestionamiento acerca de la legitimidad fue un síntoma de la vitalidad del teatro, sostiene la investigadora. Consideramos que, en un entorno tan próspero, Blancanieves y los siete pecados capitales no puede pasar inadvertida.

Bernard Dort (2009:7-12), atento a la evolución de la puesta en escena, recuerda el nuevo enfoque que surgió cuando el teatro cambió la idea de decorado por la de escenografía, valorando en mayor medida el ambiente o entorno en que se produce la representación. Sostiene que, en la primera mitad del siglo XIX, el uso de técnicas variadas transformó la escenografía y la hizo más susceptible a combinaciones diferentes, jugar con varios planos, profundidad, altura y efectos de perspectiva, con mayor dinamismo permeable a las situaciones de ocasión.

Del mismo modo, la evolución de la historia del teatro nos permite dimensionar el valor de los cambios introducidos en Blancanieves... en una escenografía vanguardista; una estética superadora, según observaciones de Dort, en una variación de los recursos motivados por el espacio vací, cubierto por múltiples recursos audiovisuales, sonoros, lumínicos, sin telón, en cercanías del público siguiendo sugerencias de las vanguardias del 60.

Acerca de los recursos desplegados en la escena, el actor Julio López, el Guardabosques, ha dejado constancia de los detalles del vestuario y de los recursos tecnológicos que se pusieron en juego, entre los que se destaca la proyección de diapositivas, la incorporación de la voz en off, produciendo la expansión y el desplazamiento de la escenografía, por la introducción de fragmentos de TV o cine.

Había al fondo del salón un gabinete bien dotado con nueva tecnología. Por ejemplo, un reflector de iluminación con al menos ocho colores. Predominaba el color caramelo y otros colores, menos la luz blanca. Ese recurso se emplea para marcar los actos, ya que no había telón. Se manejaban con luces que hacían foco en la escena. De allí también se manejaba el sonido, con las grabaciones de Betty Elizalde y Mundstock, fragmentos en off, con luz y sonido.

El escenario era simplemente una tarima sobre elevada, con escaleras que bajaban a la platea. Tenían puestos a ambos lados, unos divisorios para la entrada y salida de los personajes. El público se ubicaba en sillas dispuestas en el salón. (...) 
El vestuario tenía personal especializado para el diseño y realización de los trajes. Les Luthiers estaban con túnicas moradas. Memorizaban los textos y lucían los instrumentos informales o se destacaban en los coros que contiene la obra. (...) En el caso de Mundstok usaba dos trajes: uno de rey, de naipe, y el otro de Tarzán, también con voz en off. Cuando se sucedían las escenas, iba adaptando un vestuario como de una malla a la que la modificaba con otros suplementos para los distintos personajes. Lo mismo era con mi vestuario, con una calza verde en distintos matices, muy lindo. El vestuario era muy bonito y vistoso; especial para la obra. De eso se encargaba el vestuarista. Era una cooperativa y trabajaron para la producción del espectáculo. En una próxima entrevista le mostraré algunas fotografías, hermosas de la obra y ahí hablaremos de otros detalles.

En otro momento hacían en la escena una pila como en el rugby. Marcos Mundstock con su vestido de rey de naipe (Entrevista personal a Julio López en Buenos Aires, el 22 de octubre 2010).

Transcurridos los años, podemos destacar que el grupo ha fortalecido el texto espectacular, un enfoque que procuraba distanciarse del texto escrito previo, valorando las prácticas innovadoras que profundizaban las vivencias del actor, la creación del personaje y el recorrido de los signos hacia el interior del teatro; fenómenos estos estudiados desde distintos puntos de vista, por numerosos estudiosos y que De Marinis concibe entre sus contextos, en una interpretación aplicable a Blancanieves:

El contexto espectacular (lo inmediato) está constituido, (...) por situaciones pragmáticas y comunicativas con las que tiene que ver que el texto espectacular en distintos momentos del proceso teatral (...) la circulación. Se refiere en primer lugar a las circunstancias de enunciación y de fruición del espectáculo, pero también a sus diversas etapas genéticas (...) a las restantes actividades teatrales que circundan el momento espectacular propiamente dicho.

(...) el análisis contextual de un espectáculo del pasado tampoco puede prescindir del contexto inmediato del acontecimiento en cuestión. (De Marinis, 1997: 24-25)

Este espectáculo se construye sobre hechos políticos, culturales, sociales, psicológicos que se vivían al finalizar la década, integrados en episodios enmarcados entre los pecados capitales que amenazan a Blancanieves, abriendo ese mundo a un espectador conocedor de las referencias. Hechos tales como la Guerra Fría, la amenaza de gobiernos totalitarios, confrontación de grupos sociales diversos, el Concilio Vaticano II, los trasplantes cardíacos, el control de la natalidad, los rigores del casamiento y el divorcio o la separación, la mercantilización del espectáculo televisivo, la música popular el twist, el rock, los Beatles etc., eran realidades compartidas por el público, en un entorno que reproducía las costumbres locales, como la estrofa de Martín Fierro, referida a la envidia en una parodia del gaucho cantor, o la Cumparsita, con interpretación del tango.

Al referirse a la semiótica de la escena, Lotman (2000) explica la conformación de los sistemas de signos que poseen un profundo carácter social, sobre la comprensión entre los seres humanos y sobre las formas de codificación sociocultural. Esos sistemas de signos en un entramado escenográfico de diversos elementos, crea un intenso efecto cómico, que supieron explotar apelando a ese contexto sociocultural que se vivía en el país. Los signos puestos en la escena cambian su convencionalidad dotando al discurso de particularidades existentes entre las vivencias del público curioso por la novedad. 
Se construyó así una nueva dimensión en la comunicación teatral argentina entre un actor renovado ante un espectador más participativo en acontecimientos cotidianos. Sobre las actitudes del espectador, Lotman observa que "sean cuales sean sus vivencias, permanece inmóvil en la butaca (...) las personas que están en la sala el acontecimiento son "un signo de sí mismo". Elabora las acciones de los personajes que dialogan entre sí y en un "diálogo no manifiesto con el público", logrando una participación activa de la comunicación y produciendo la vitalidad del espectáculo: "un acto colectivo de conciencia que se consuma en el teatro". (Lotman,2000:70) Asimismo, puntualiza que "el lenguaje del teatro se forma de las tradiciones culturales nacionales, y es natural que el hombre inmerso en esa misma tradición cultural sienta en menor medida la especificidad de ese lenguaje; (...) Una de las bases del lenguaje teatral es lo específico del espacio artístico de la escena. Precisamente ella es la que da el tipo y la medida a la convencionalidad teatral". El grupo teatral ha puesto de manifiesto un talento especial para lograr una comunicación exitosa y representativa de su tiempo, dotada de mayor mérito a través de los años a la luz de otras investigaciones. Afirma Lotman que "solo en el teatro el concepto de ensemble se convierte en uno de los principios constructivos fundamentales." (Lotman, 2000: 82).

Josette Féral indaga en el "estudio genético de la puesta en escena" y menciona aspectos del proceso que resultan fundamentales, muchas veces ocultos, como son las instancias previas de la obra acabada. Destaca que:

El trabajo "genealógico" de preparación, las etapas del trabajo de construcción de la puesta en escena, la búsqueda que el actor efectúa acerca de su personaje, las dudas, tachaduras, elecciones, hallazgos -que logra el trabajo colectivo -son fundamentales para comprender la obra. Aclaran el sentido y permiten ver la creación en acción: creación de la puesta en escena, creación de un rol, creación de un personaje. A esos saberes periféricos seguramente se agrega todo el trabajo práctico de la puesta en escena, el trabajo con los actores, el trabajo sobre la narración, sobre el texto, el espacio, el vestuario, la iluminación, la escenografía, dicho de otro modo, el trabajo de ensayo mismo que impone opciones, permite hallazgos puntuales (2004:27-28).

Se trata de un proceso complejo que se hace más minucioso por los ensamblajes de fragmentos corales y musicales, voz en off, buscando efectos humorísticos determinados, los que, por los testimonios de los integrantes y entrevistas, podemos revalorizar hoy en los inicios de una metodología propia, de la que han dejado constancias explicando los secretos de ese arte.

Ese delicado entramado de efectos resulta, para Féral y otros investigadores, momentos de acierto en la creación teatral en que "la investigación genética pone el acento en la producción más que en el producto terminado, en la escritura más que en lo escrito, en la textualidad más que en el texto, en la multiplicidad más que en la unicidad, en lo virtual más que en lo real, en lo dinámico más que lo estático, en la operación más que en la obra, en la génesis." (Féral, 2004:31); principios básicos del trabajo experimental del grupo. En esas prácticas se produjo el hallazgo de un estilo cuyas identidades supieron contextualizar en sus espectáculos durante todos estos años, hasta el reciente reconocimiento al ser incluidos en los archivos del Instituto Cervantes.

En esa dirección, reconocemos con Bernard Dort, etapas anteriores del espectáculo que se logra con determinadas condiciones, "un orden preexistente a la representación teatral, (...) si no es que al texto mismo. La forma está dada de antemano, intangible" que se encarna y es "esta forma que contiene en sí misma todo el sentido 
del espectáculo" (Dort, 2009: 7-12) guarda un sentido ritual propio del teatro en sus orígenes. Previo a la puesta en escena, el grupo tuvo un orden preestablecido de acuerdos artísticos que favoreció la confluencia de ideas revitalizadas en las prácticas.

El Di Tella tomó el carácter de un teatro independiente, observa King (2007), pues con el apoyo de la música y la proyección de diapositivas, se logró conformar un sistema audiovisual empleado en diferentes actividades ya que el personal técnico acompañaba los espectáculos. El instituto llevó a cabo durante diez años un programa de subvención a las artes que ha sido destacado a través del tiempo y tiene a los integrantes del grupo como protagonistas.

El impacto que produjo la proyección de diapositivas en esos años resulta un avance destacable por su originalidad y expansión del espacio teatral, estimulando la memoria del espectador con imágenes del pasado, en el cine o la TV., de fuerte efecto visual ambientador con luz y sonido que condiciona el desempeño de los actores y potencia su vestuario (Ubersfeld, 1997). La proyección de imágenes implica una adecuación a la verosimilitud del cuadro. Una ambigüedad del efecto que actúa en las fronteras de la acción. Sostiene Pavis (1998: 2) que "toda tecnología, toda informática es un cuerpo extraño al corazón de la escena teatral" introduciendo saltos en el discurso tensionado por el lugar de procedencia, que contamina la escena. La diapositiva en el relato del espectáculo ingresa con asociaciones intertextuales que se diversifican en la recepción del público en un concepto multifacético que modifica todos los signos de la escena.

Así resulta que, en la escena cuarta de La Ira, la diapositiva que ilustra la imagen de la tribuna en un partido de fútbol, se complementa con efectos sonoros y corales que confluyen hacia el acoso de Blancanieves que quiere huir.

Del mismo modo, las fotografías ilustran el vestuario con detalles alusivos a la fábula tradicional, con contrastes humorísticos notables en la figura de Tarzán o bien la vestimenta de los reyes de naipe que se visualizan en la fotografía original. Se aprecia el despliegue escenográfico, la distribución de los personajes ocupando todo el espacio de la tarima, inclusive los personajes-músicos.

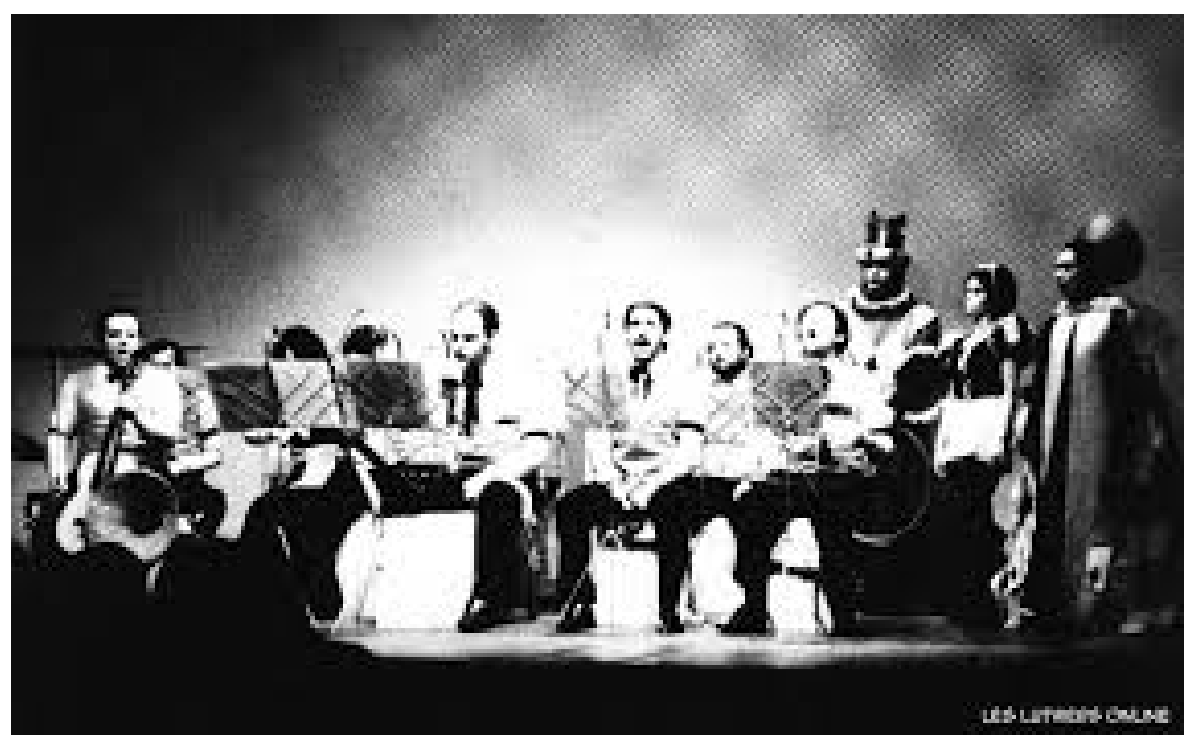




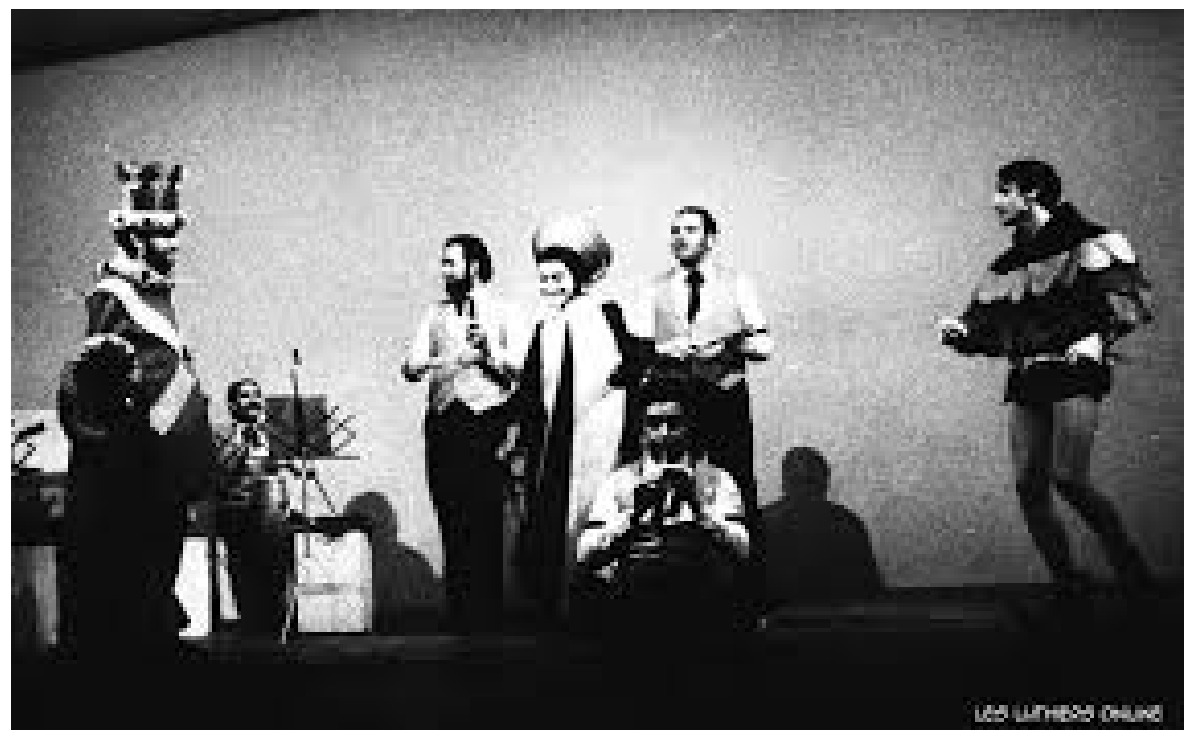

Fotos: gentileza del sitio https://lesluthiers.org/verobra.php?ID=20. Consultado 21 de octubre 2019

Osvaldo Pellettieri (2003), en su enfoque de periodización, ha desarrollado las particularidades del campo teatral argentino durante el siglo XX, mostrando los cambios respecto del teatro del período anterior que, en muchas circunstancias, continuaba vigente en simultáneo con la renovada experimentación de la vanguardia del Instituto Di Tella, distanciada de los cánones vigentes. Los cambios corrían en paralelo con un momento de modernización del país y nuevas tendencias de la escena en el mundo, conmovido por la intertextualidad de los happenings, las performances, integrados a los medios de comunicación y los avances del cine. Temas como la incomunicación y el enfrentamiento generacional se asocian a los pecados capitales, que son un símbolo de las transgresiones que se vivían como amenazas del pensamiento laico sobre parámetros de fondo religioso (Oratorio Profano), en medio de grandes transformaciones de la cultura universal. Los pecados también aparecen en otros discursos de la época, con particularidades semejantes a esta obra, intentando compartir ese debate con el público (Cf. Gudiño Kieffer, 1972).

Eran tiempos que habilitaban nuevos lenguajes sorteando dificultades propias de la diversidad cultural en el espacio compartido bajo diferentes códigos, fruto de la trayectoria personal de cantantes, locutores o potenciales actores en situación. Fueron cambios profundos para el teatro argentino que ubican al grupo en un lugar relevante. En el marco de un sistema teatral amplio, Pellettieri ve al "teatro argentino como proceso de cambios y continuidades" (2003:14,15), por influencias o por la genialidad personal, marco en el cual se encuentra de manera muy marcada, esta obra.

Tal es el caso de la confluencia de factores que favoreció a estos artistas para concretar una versión poco difundida de Blancanieves... en el contexto en que se concreta la fábula ideada por Les Luthiers, en que el humor actúa como factor esencial entre las contradicciones de la acción dramática y las conductas de los personajes. Elegir la trama de un cuento, en el caso de Blancanieves..., muestra el cuestionamiento implícito de los estereotipos masculino y femenino que alimentan hoy los estudios de género, de tanta vigencia, al poner en tela de juicio las conductas aceptadas socialmente sobre las creencias tradicionales que se presentan en la fábula. El teatro puso en escena la vibración de los conflictos, el miedo, los deseos con particular acierto, generando la risa en los espectadores. 
Pellettieri describe el movimiento propio de nuestro sistema teatral, incluyendo a una determinada comunidad de receptores, con adecuaciones acordes a las demandas de la cultura argentina. Un proceso que se cumple de manera evocativa con el recitado de Martín Fierro o de las vivencias del tango y la canción popular de moda impuesta por programas televisivos.

Las máquinas de proyección de diapositivas fueron incorporadas a la representación de Blancanieves... con tres pantallas que impactaron extendiendo las dimensiones de un espacio despojado, que se transformaba desde el espacio vacío a la plenitud de la puesta en escena.

La escenografía ha transformado la condición escénica, ya que incorpora como un elemento más, los músicos al nivel de los actores, personajes participantes según los momentos de la acción, con las adecuaciones sonoras se intercala la voz en off, con técnicas radiales que se vinculan a los acontecimientos en calidad de personajes en un relato sonoro desde otra dimensión. Los fragmentos reproducidos con técnicas radiales resultan del entrenamiento que realizaban Marcos Mundstock y Betty Elizalde como locutores, grabados en un ámbito radial de la Ciudad de Buenos Aires, intercalados en el guión de Blancanieves..., simulando los efectos del psicoanálisis en esos diálogos personales en que la protagonista angustiada (Betty) busca interpretar sus conflictos a la luz de las sugerencias del psicoanalista (Mundstock). Se trataba de fragmentos interrumpidos y, en forma de enclave con el hilo de la fábula, lograban así la prolongación de la escenografía más allá de la sala. La dimensión auditiva proporcionaba a la representación otra perspectiva de los hechos que estimularon el rol de un espectador auditivo, activo y reflexivo que debe integrar el relato.

Aunque no se ha conservado toda la documentación donde se pudiera apreciar la interacción de recursos que se distinguen en la escucha, por momentos se pueden asociar las fotografías y el texto a los acontecimientos y eventualmente la gestualidad a través de la risa. La tecnología ha facilitado el archivo que se encuentra en el sitio Web reservado a la obra. ${ }^{1}$

García Barrientos, al referirse al teatro del futuro, considera las nuevas tecnologías y advierte las modificaciones, aunque afirma que "es quizás el género más reacio a metamorfosearse, o el más fiel a sí mismo". Nota que los cambios en la historia del teatro, tanto las representaciones como los textos dramáticos "permanecen sustancialmente idénticos en los últimos quinientos años, de los griegos a hoy mismo, por lo menos en el sentido de que es más fuerte el principio de identidad o cohesión que el de diferencias o desintegración de un corpus del teatro occidental, representado o escrito" (2009:12).

Siguiendo la inspiración de los pecados capitales, resulta interesante descubrir aspectos de la realidad delimitada por ese eje temático que se mantiene a través del tiempo, desde la Edad Media y el Renacimiento a la actualidad. En consecuencia, las reflexiones acerca de los pecados resultaban esclarecedoras para interpretar las connotaciones derivadas de un cuento tradicional, modificando el contexto proclive a los sucesos cotidianos, como una manera de dotar al signo teatral de variadas valoraciones morales que alimentan la interioridad humana afectada por situaciones universales de todos los tiempos, profundidades filosóficas que hacen trascendente esta obra y a sus creadores.

$1 \mathrm{https}$ ://lesluthiers.org/verobra.php?ID=20 Versiones 1969/70 Reparto, texto, fotografías. Consultado 21 de octubre 2019 https://lesluthiersdelaweb.es.tl/blancanieves-y-los-7-pecados-capitales.htm. Consultado 21 de octubre 2019 https://static.lesluthiers.org/audios/Obras/blancanieves.mp3 Versión auditiva del espectáculo. Consultado 21 de octubre 2019 


\section{Bibliografía}

»Dort, B. (2009). Condición Sociológica de la puesta en escena teatral [Traducción de Laure Riviére y Rodolfo Obregón] Cuadernos de Ensayo Teatral N 11. México D.F.: Paso de Gato.

" García Barrientos, J.L. (2009). El teatro del futuro. Cuaderno de Ensayo Teatral N ${ }^{\circ}$ 4. México D.F.: Paso de Gato.

» Gudiño Kieffer, E. (1972). Guía de Pecadores. Buenos Aires: Editorial Losada.

»King, J. (2007). El Di tella y el desarrollo cultural argentino en la década del sesenta. Buenos Aires: Asunto Impreso Ediciones.

» Kostzer, K. (2016). La generación Di Tella y otras intoxicaciones. Buenos Aires: Eudeba Proteatro.

»Lotman,I. (2000). "Semiótica de la escena”. En La Semiósfera III - Semiótica de las artes y de la cultura (pp. 57-84) [Selección y traducción del ruso por Desiderio Navarro]. Madrid: Cátedra.

"Masana, S. (2005). Gerardo Masana y la Fundación Les Luthiers [Con CD de canciones inéditas]. Buenos Aires: Grupo Norma.

» Pavis, P. (1998). Teatro Contemporáneo imágenes y voces. Santiago de Chile: Universidad Arcis.

» Pavis, P. (200o). El análisis de los espectáculos -Teatro, mimo, danza y cine. Barcelona: Paidós.

"Pellettieri, O. (2003). Historia del Teatro Argentino en Buenos Aires. Volumen IV - La Segunda modernidad (1949-1976). Buenos Aires: Galerna.

» Pinta, M. F. (2013). Teatro expandido en el Di Tella -La escena experimental argentina en los años 6o. Buenos Aires: Editorial Biblos.

»Samper Pisano, D. (2014). Les Luthiers de la L a la S. Bs.As.: Ediciones la Flor.

» Trastoy, B. y P. Zayas de Lima (2006). Lenguajes escénicos, Buenos Aires, Prometeo Libros.

»Ubersfeld, A. (1997). La escuela del espectador. Buenos Aires: Galerna.

»Zayas de Lima, P. (1995). Carlos Somigliana Teatro histórico- Teatro político. Bs. As.: Editorial Fray Mocho. 